The Geneva Papers on Risk and Insurance, 18 (No. 69, October 1993), 388 - 398

\title{
Specialization and Diversification in Financial Services Some Recent, Practical Experiences in the Netherlands
}

\author{
by J.H. Holsboer*
}

The recent developments in the financial services industry in Europe towards bancassurance or Allfinanz are characterized by many people as revolutionary. Against this background I have been asked to address you today on the topic of 'specialization and diversification in financial services'. I will try not to approach this subject too much from a theoretical point of view, but more from my own practical experiences with ING Group, the financial services company based in the Netherlands. I will use the perspective of the insurer and explain why Nationale-Nederlanden chose to diversify into the banking industry. Thereby I will focus primarily on retail and marketing aspects, although also the other dimensions of diversification in the financial services industry should not be neglected. Next, I will talk about the consequences of this diversification in terms of strategy and structure. Finally, I will put forward some challenges for further economic analysis of the merger creating ING Group, because I think the ING case is a prime example of what is happening in the financial services industry today and of the choices that can be made in this turbulent environment.

\section{The concepts of specialization and diversification in relation to bancassurance strategies}

For the practical purposes of my speech, I describe diversification as the movement into activities outside one's own industry, whereas specialization is the concentration of activities on a specific product range or market segment within an industry. The title of my presentation seems to imply that specialization and diversification are mutually exclusive strategic options. In my view this is not necessarily so. A diversified group of financial services companies is often a combination of business units in specialized segments of the financial services industry.

In that context, diversification is a corporate movement into another industry, whereas specialization is the way a business unit can distinguish itself from competitors within the same industry, even within the same group of business units. In other words, diversification is a corporate strategy, while specialization is a strategy conducted at the level of the business unit.

* Member Executive Board, International Nederlanden Group, The Hague. 12th Geneva Lecture of the Geneva Association, Rotterdam, September 21, 1993. 
The strategic question behind diversification is whether the combination of activities in different industries creates additional economic value. An important reason for diversification in the financial services industry is to spread risks and sources of revenues. Other motives which are often mentioned are the possibilities of more efficient capital allocation and sharing the use of management and information technology capabilities. Also, size is of crucial importance to achieve the necessary economies of scale and economies and qualities of scope in a diversified environment (at the corporate level as well as the business unit level). This means that if a company wants to diversify efficiently, it will have to do this on a large enough scale.

Bancassurance offers financial services companies new possibilities for diversification and specialization, as is illustrated in a simplified manner in the following diagram:

\section{Industrials colums in financial services}
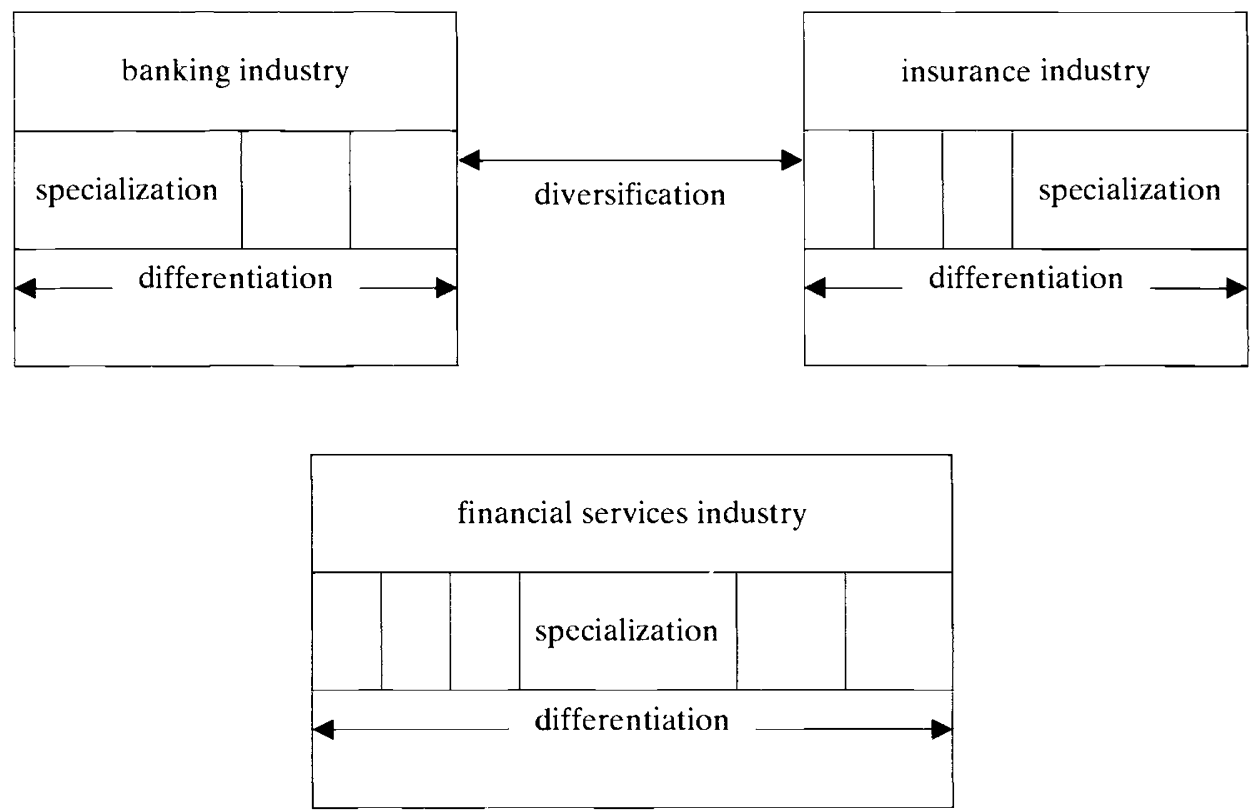

If you regard banking and insurance as separate industries, banks and insurers can diversify into the other industry. If this is done on a large enough scale, driven by market developments and institutional changes, it leads to a more or less integratcd financial services industry, in which new possibilities for specialization and differentiation arise with regard to products, distribution and back-office operations.

As far as the retail and small commercial markets are concerned, an important reason for the fact that banking and insurance have historically developed as separate industries can be found in the institutional impediments governments have imposed on links between 
banks and insurers. The development towards one common market with a free flow of capital and services has led supervisory authorities in the EC countries to lift many of these restrictions. This deregulation process has had quite an impact. I will illustrate this by using the Dutch situation as an example.

\section{The present Dutch situation}

For the Dutch financial services industry the most important event as regards institutional change has been the liberalization of what was known as the Structure Regime. Until 1990, banks and insurers were not allowed to participate in each other's capital for more than $15 \%$. Soon after this restriction was lifted, an unprecedented concentration and diversification drive occurred:

- ABN and AMRO merged to become the largest Dutch bank and started their own insurance operation as the intended prime supplier of insurance services distributed through their branch network.

- The second largest bank RABO merged with the insurer Interpolis and entered into a cooperation agreement with the leading direct writing insurers Centraal Beheer and Avero.

- Amev merged with the largest Dutch savings bank VSB and soon thereafter with the Belgian insurer AG, founding the Fortis Group.

- Nationale-Nederlanden and NMB Postbank Group merged to form ING Group. As a result NMB Postbank Group changed its name to ING Bank.

And on a smaller scale:

* 3 union-linked banks and 2 union-linked insurers merged to form the Reaal Group;

* Delta Lloyd, Stad Rotterdam, Ohra started their own banking operation;

* finally, Aegon is active with its specialized savings company Spaarbeleg (partly as a direct writer) and also owns a bank with a full licence as well as a mortgage bank.

The result of the liberalization of the Structure Regime is that in the Netherlands:

- banks representing some $80 \%$ of the banking activities (based on total assets) merged with insurance companies or started their own insurance carrier,

- insurers representing approximately $50 \%$ of the insurance activities (based upon premium income) merged with or acquired a bank,

which, I feel, can be described as a real landslide in the financial services market in this country.

\section{The European dimension}

For companies operating in this part of the world, the European dimension is of key importance. The creation of a common market has changed the strategic perspective of financial services companies. They now have to choose to stick to a regional strategy, which limits the possibilities of growth, or to adopt a pan-European strategy.

Given their relatively small home market, Dutch financial services companies are at a disadvantage in terms of 'Eurocompetition'. With a home market of only 15 million people the starting position is substantially less favourable than, for instance, for their German, French, British and Italian competitors. 
The realization of the European market, and ultimately a European Monetary Union, will have as profound an effect on the financial markets as the Europe 1992 programme has had.

I refer, amongst others, to the harmonization of supervisory regulation, the foundation of a European central bank, the disappearance of intra-European foreign exchange dealing (although this may seem far away at the moment), the integration of payment systems, the influence on capital markets and increasing price transparency.

In the financial services industry in Europe we see a process of consolidation taking place. On a national level, this process is most spectacular in the smaller EC countries. I have demonstrated this for the Netherlands, but also in other countries, for example in Belgium, similar market developments are taking place. The consolidation process will continue on a regional (cross-border) level and eventually also on a European level.

The shape this cross-border cooperation takes is in the majority of cases a substantial capital participation combined with cooperation agreements and in some cases a joint venture. Today, many cross-border alliances have emerged, also from the Netherlands. To give you some examples:

- RABO established relationships with the Raiffeisenbank in Germany, Crédit Agricole in France, Lloyds' Bank in England and a major Spanish financial institution. There is a similar network for insurances with an agricultural background.

- Avero-Centraal Beheer with Friends' Provident in England and Occidental Holding in Portugal.

- Fortis joined forces with Caixa in Spain and will probably team up with ASLK in Belgium.

\section{The merger creating ING Group}

Against these trends in Europe, Nationale-Nederlanden, confronted in 1990 with the opportunity of a strategic alliance with the NMB Postbank Group, the third largest bank in the Netherlands which was looking for further expansion took this opportunity and opted for a merger, basically for two reasons:

- Offensive :

Nationale-Nederlanden wanted to have a stronger home base for international expansion, especially with regard to European developments, and wanted to take the lead in the development of bancassurance, especially in retail and small commercial markets, by using the joint distribution channels and by combining knowledge, skills, systems and management.

- But also defensive:

The restrictions on Postbank (the former state bank, which had merged with NMB Bank to form NMB Postbank Group) for selling insurance were lifted. Moreover, with a growing share of insurance production, especially life, of some $15 \%$ via bank branches and with banks increasingly being committed to their own insurance carrier, NationaleNederlanden regarded the opportunity of combining banking and insurance as the most attractive strategy.

We aimed at a full merger, because in our opinion one strategic vision and one management structure would create the environment for future growth and achieving an integrated financial services approach. It would mean a total commitment and focus on an 
integrated financial services strategy and marketing, instead of just a commercial agreement for the home market, whereas such an agreement is by nature restricted in time and scope. A merger would also mean greater continuity and more flexibility with regard to market changes than a joint venture would have meant.

Without unity in commercial policies and joint responsibility for financial results, strategic interests are bound to diverge. The life cycle of strategic joint ventures, also in our industry, has shown that after a few years cracks emerge in such a relationship. There are even findings that $75 \%$ of all alliances and take-over's eventually fail. We did not want to base our core business of integrated financial services in the retail and small commercial markets on a looser form of cooperation than a fuller merger.

\section{ING Group's integrated financial services strategy for the retail and small commercial markets}

The basic consideration behind the merger creating ING Group is that, as far as the retail and the small commercial markets are concerned, we view banking and insurance as part of one and the same market for financial services. In our opinion the regulatory division between banking and insurance in these markets is an artificial one for marketing strategic purposes. It is especially the institutional separation of banking and insurance that has led to the development of specialized distribution channels and predominantly product-oriented back-offices for each industries.

Traditional organizational structures are increasingly being put under pressure. New combination of banking and insurance products have become feasible and have already been developed, such as the combination of products like car insurance/car finance, fire insurance/mortgage, life/savings products, student financial services packages, etc.

Basically we believe demand side market developments will lead to integrated financial (retail)markets : the customer doesn't necessarily want to deal with a bank and an insurer, he wants to be catered for with financial services according to his needs and to choose a distribution channel (or several), which he regards as the most appealing for the specific service, to supply him with these services. This will have to be done in a profitable way, though. And on this border between market demand and profitability requirements new possibilities of innovation will have to be developed.

The strategic objective of our diversification process is to anticipate this market development and to realize what we call an 'integrated' financial services approach. Our ambition is to go beyond 'just' selling insurance products through the bank branches and selling banking products through the insurance distribution channels. We want to offer our clients through every distribution channel a range of financial services, which are specifically developed and labelled for that particular channel and satisfy the particular needs of the customer in that market segment.

Within ING Group's home market we have the potential to combine each financial service product with all existing distribution channels to meet new market demands. The presence of the various insurance companies and labels in the retail and small business markets perfectly matches the various banking activities. Our first pilot experiences with bancassurance (selling tailor-made insurance services to clients of the banks) and assurbanque (selling banking products through the insurance distribution channels) are exceeding our expectations. And we will use this knowledge and experience in the home market also for further international expansion. 


\section{Structure follows strategy: organizational consequences of a diversification strategy}

So far, I have talked about specialization and diversification from a corporate strategic and marketing point of view. I will now deal with the organizational consequences of a diversification strategy and the way in which we intend to create the requisite conditions to become a truly integrated financial services company.

ING Group intends to take the next step towards full implementation of the concept of an integrated financial services group. Experience over the years with our companies in the Netherlands and abroad has taught us that cooperation between independent business units does not come easily or spontaneously, particularly when the swing from product orientation to client orientation has to be made. Strategic cooperation between business units really takes off from the moment that a joint management responsibility has been implemented.

As in most insurance and bank organizations, our present organizational structure is basically product-oriented, as is shown in the following diagram:

Precent corporate structure

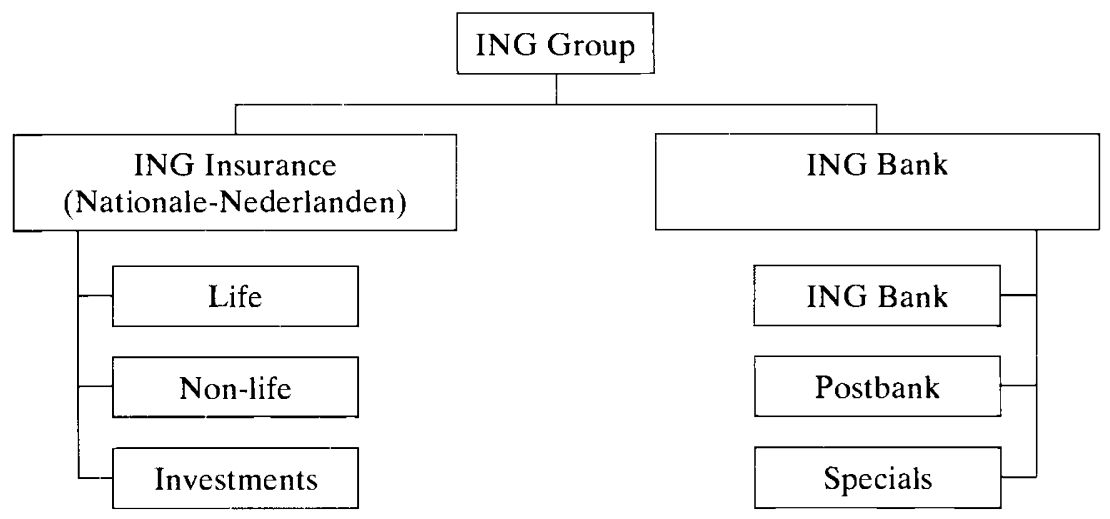

Currently ING Group consists of two operational sub-holding companies, ING Bank and ING Insurance. It is a complicated structure with three executive boards and three supervisory boards of outside directors. Although some members of the executive board of ING Group are also members of the executive boards of the bank or the insurer, the executive board of ING Group is the only organizational level which has an overview of both banking and insurance activities. The other levels are committed to either banking or insurance. The sale of insurance products through bank branches or the sale of banking products by insurance intermediaries can only be achieved by cooperation across that organizational barrier. 
In the intended new structure the organization will be completely market-driven for banking and insurance services combined:

New operational structure

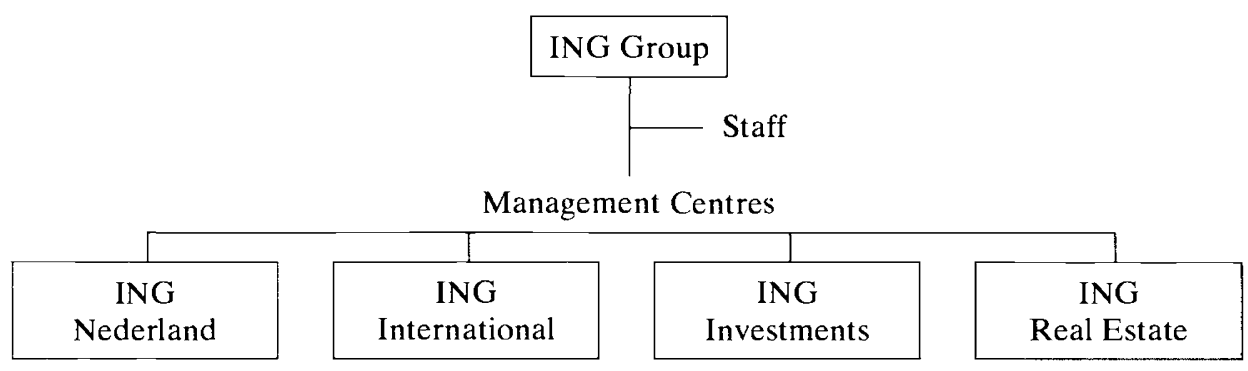

Operational structure for the Netherlands

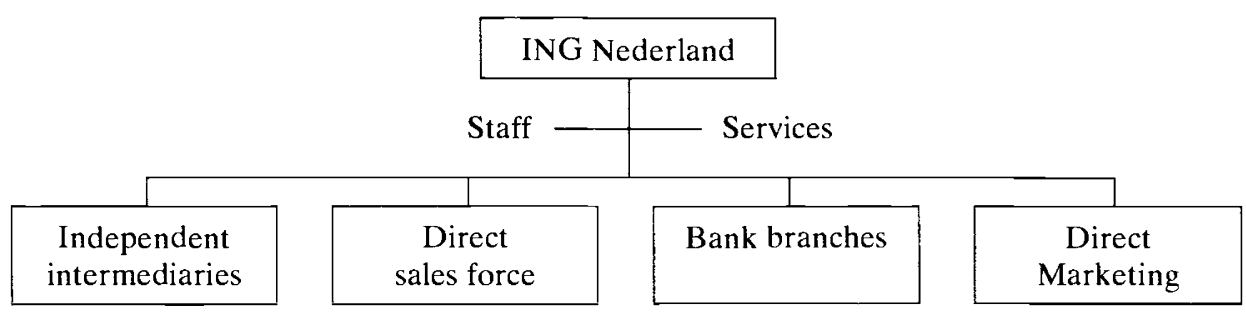

In the new operational structure there will be one executive board and one supervisory board of outside directors. The organization is divided into four 'management centres':

- Within ING Nederland business units will be grouped by distribution channels (independent intermediaries, direct sales force, bank branches and direct marketing). The management of ING Nederland has to optimize the product/market combinations for each distribution channel and between the channels.

- ING International consists of the international activities of ING Bank and ING Insurance.

- ING Investments, in which the responsibility for asset/liability management, the capital market operations of the bank (treasury/trading and investment banking) and the investments operations of the Group are brought together as 'pools of excellence'.

- ING Real Estate, combining the real estate activities of the bank and the insurer.

The management centres coordinate the activities of the various business units. The business units themselves are not directly affected by the reorganization, except for reporting lines. These business units provide specialized financial services, targeted to specific market segments. Decentralized responsibility for the business units remains the cornerstone of our management philosophy. Top management performs the role of integrator by coordinating 
banking and insurance activities, stimulating cooperation and assisting in decision-making. ING Group thus serves to promote the overall picture of the company, balancing the specialized outlook of the various activities.

In the discussion which led to the new structure, the implications of the reorganization with regard to supervisory regulation were of great importance. At least in the Netherlands, supervision for insurers is bottom-up (on individual companies) and supervision for banks is top-down on a consolidated level. We have solved this problem by leaving the corporate legal structure unchanged. This means that legally the present statutory sub-holdings of the bank and the insurer will continue to exist. Some executive board members, as well as some supervisory board members, will serve as insurers, while others will be the ultimate responsible bankers for regulatory purposes.

\section{Distribution policy}

As I already mentioned, the basic objective of the new operational structure, especially for the Netherlands, is a transformation from a product-oriented to a market-oriented organization structure. This is visualized in the following diagrams:

from:

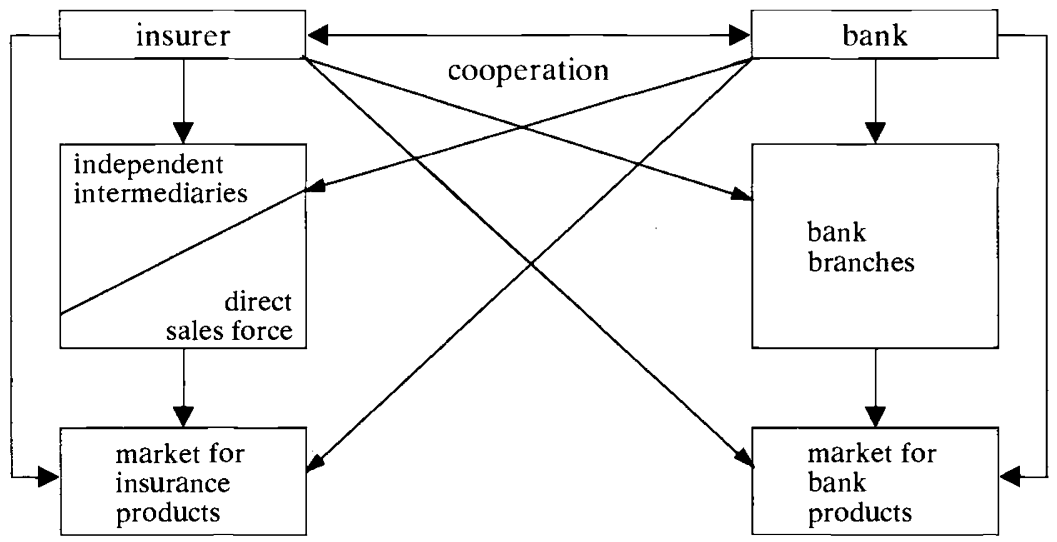

to:

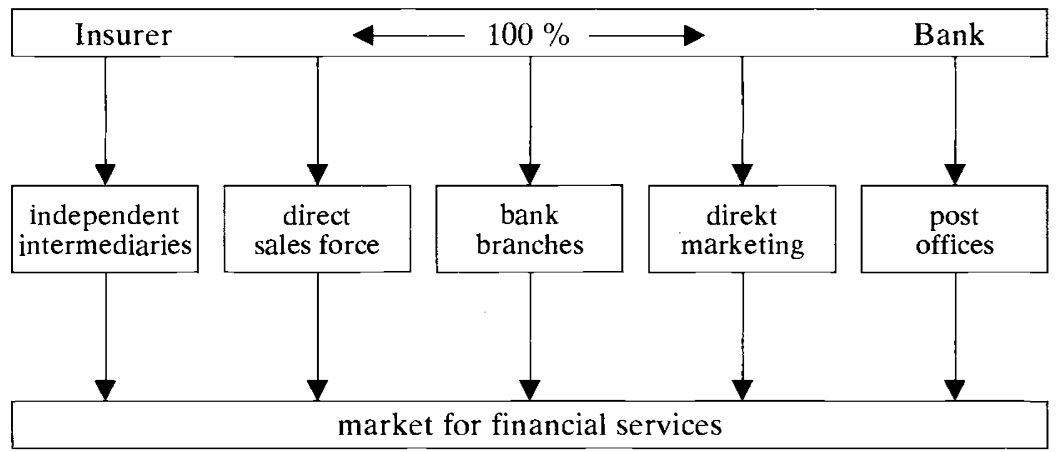


In principle there are no organizational barriers left between banking and insurance, but only between distribution channels. Between distribution channels there will often be competition with different services being offered to the same client. Both banking and insurance products are sold through all distribution channels, as is illustrated in the following diagram :

\section{Integrated financial services \\ Dutch market: Optimal use of ING Group's main distribution channels}

10,000 Independent insurance intermediaries (NN)

1,200 Direct sales force (RVS Insurance)

600 Bank agencies NMS

400 ING Bank branches

Postbank Direct marketing (database 6,500,000 clients)

2,100 PTT post offices and agencies (PTT/Postbank)

1,000 ATM's (Automated Teiler Machines)

$\mathrm{B}=$ Banking products $\quad \mathrm{I}=$ Insurance products $\quad \forall=$ new $\quad *$ = existing

From this diagram it is clear that the specialization on the retail market by Postbank and on the small commercial market by the former NMB Bank perfectly matches the specialization in the insurance markets by Nationale-Nederlanden. Which again indicates that not every bank is a logical partner for every insurer who wants to diversify.

There is of course a danger of cannibalism. It takes time to proceed to the optimum point in market volume and margins per distribution channel. For that reason we have conducted a fundamental market analysis of the development of the Dutch retail market and formulated integrated marketing strategies in order to strengthen, and when possible improve, our service and thus our position in this market, both in terms of profitability and market share.

The restructuring of the organization in the Netherlands (to be implemented by the end of this year) is done with a focus on distribution, but on a longer term we also expect to be able to make better and more efficient use of front-office versus back-office facilities.

For example, for mortgage operations we now have five administration systems for the different labels in this market. In the future we think there are definite possibilities for cost efficiencies through realignment of these systems. In this way the new structure aims to provide the organizational framework required to implement the concept of integrated financial services and at the same time cash in on the maximum attainable synergies, both in terms of costs and revenues. In our opinion it is imperative, also for a diversified financial services company, to become the low-cost producer in each speciálized market segment.

\section{Integrated financial services : a new challenge for economic analysis}

Integrated financial services are not only a revolutionary development in the financial services industry, but also poses new challenges to economic theory. Up to now, we experience that specialized investment analysts are either insurance experts or bank experts. So we are often compared with a bank or just an insurance operation. The same applies for investment managers. 
The merger creating ING Group and similar mergers and alliances between banks and insurers leave interesting questions open for further economic analysis. It is a prime example where real world developments may influence economic theory or at least provide professors and students with unique case study material which in turn could assist in practical decisionmaking. It is not only a learning process for management but also for banking and insurance economists.

So I would be missing an opportunity here if I did not give this audience some indications of the most relevant fields in economics where the phenomenon of integrated financial services poses new questions for further study and analysis.

\section{Industrial economics}

An important common economic function of banks and (life) insurers in the financial system is the transfer, through demand and supply of financial services, of surplus funds from savers to investors. In this process these funds are transformed, both by banks and insurers, in terms of maturity, risk and size.

What will integrated financial companies mean for competitive forces in financial markets and their structure, conduct and economic performance? What will be the impact on demand for and supply of financial services when distribution channels and products are differentiated? And when these questions are adequately answered, what will that imply for corporate strategies of financial services institutions?

\section{Financial intermediation theory}

Banks and insurers have in common that financial intermediation is at the heart of their production process. Economic value is added by financial asset and risk transformation through issuing or acquiring assets, assuming liabilities and pooling of financial risks. What happens if these processes are brought together in one financial services group? Banks and insurers have different risk profiles requiring different risk management tools and policies. Generally speaking, the risks of banks are concentrated on the asset-side and the risks of insurers on the liability-side of the balance sheet. Of course every effort has to and will be made to avoid contamination of these risks, to apply proper Chinese walls and to comply with all pertinent regulations. What is the resulting risk profile of a merged financial services group? We have made this choice and we are convinced that we now have better possibilities to spread risks and to control them. But we would welcome contributions in this field from the research side.

\section{Financial and management accounting theory}

Accounting practices, especially in the insurance industry, have changed rapidly in recent years. What are the appropriate accounting standards for public financial statements of integrated financial services institutions? What public financial information is needed to ensure that users of such information obtain a fair view of the financial health and business risks of these companies? What are the information needs of the management of integrated financial services companies to be able to monitor and control the economic, distribution and product performance of their organization?

\section{Administrative organization and information technology}

Integrated financial services pose new requirements to back office and data handling technology, in particular when new distribution channels are entered and innovative bank and insurance product combinations are introduced. 
How could information theory contribute to the design and the development of information systems to efficiently face these new requirements?

These are some obvious questions we encounter in our present situation. There are of course a lot of other issues. For example, questions related to human resource management theories.

\section{Final remarks}

I will conclude my presentation with some final remarks. As far as the Netherlands is concerned, I can make the following observations:

- Diversified insurers and banks, i.e. integrated financial services groups, have become a reality and in fact the major suppliers in the Dutch market.

- Integrated financial services, however, are no panacea for all insurers. Its use and practicability will heavily depend on size and market position in order to achieve the economies and qualities of scale per distribution channel and per market segment, which competition requires.

- For specialized insurance companies (by product or by market) excellent opportunities remain available.

It might seem that competition is driven by corporate strategies. And indeed, there are of course strong dynamics in the financial services sector that generate change. The real competition, however, is at the business unit level. In the end the consumers decide which strategy will be successful and which will fail. And in that process the implementation of strategy and the delivery of your products and services to the customers is much more important than the strategy of specialization or diversification itself.

I thank you for your attention. 